\title{
Challenges in English Teaching and Learning in Colombia
}

\author{
Zaily Patricia Del Toro ${ }^{1,2}$, Ana Carolina Mercado ${ }^{3}$, Milton Pájaro Manjarres ${ }^{1,4}$, Luis Fernando Noriega ${ }^{1,5}$, \\ Willington Watts ${ }^{1,5}$ \& Milton Lopez Sanchez ${ }^{1,6}$ \\ ${ }^{1}$ Universidad de Córdoba, Montería, Córdoba, Colombia \\ ${ }^{2}$ Institución Educativa Nacional Jose María Cordoba, Montería, Córdoba, Colombia \\ ${ }^{3}$ Institución Educativa Camilo Torres, Montería, Córdoba, Colombia \\ ${ }^{4}$ Institución Educativa Antonia Santos, Montería, Córdoba, Colombia \\ ${ }^{5}$ Institución Educativa La Pradera, Montería, Córdoba, Colombia \\ ${ }^{6}$ Institución Educativa Rafael Nuñez, Montería, Córdoba, Colombia \\ Correspondence: Milton Pájaro Manjarres, Calle 43 B \# 17 Bis-22 Barrio Villa Nova, Montería, Córdoba, \\ Colombia.
}

Received: February 9, 2019 Accepted: March 8, 2019 Online Published: March 12, 2019

doi: 10.5539/elt.v12n4p57 URL: https://doi.org/10.5539/elt.v12n4p57

\begin{abstract}
This article presents a reflection on the educational scenario that permeates the teaching of English as a foreign language (EFL) in its political, methodological, didactic, curricular and investigative dimensions. A description of the current English reading comprehension level in the national context is presented. On the other hand, from a transformative conception in which educational practices must be developed, different elements aiming to the development of formative practices are explored. This is achieved, with the active participation of all the subjects that participate in the educational process by conducting research, which plays a fundamental role that contributes to achieve the emancipation of human beings and the transformation of the environment where they live.

Furthermore, this article invites readers to think about and transform the pedagogical practices that are around the teaching of English as a foreign language in Colombia, Latin America and the whole world. This is possible to be achieved, from a resignification of the curriculum and emerging didactics, focused on research and the multidimensionality of human beings.
\end{abstract}

Keywords: English, foreign language, critical reading comprehension, curriculum, didactics, emerging didactics

\section{Introduction}

The advent of the 21 st century has brought different changes mainly characterized by advances in science and technology combined with a renewed vision of the human being, which has deeply impacted and reshaped everyday life. Besides that, it is necessary to add the increasingly aggressive globalization phenomenon that has positioned English as the world language. Although it is not the most widely spoken language around the world, it is considered a lingua franca or vehicular language. For this reason, the amount of information written in English that we need to address in the different areas of our life is increasing. However, this reality has revealed the low levels of reading comprehension in this language, a problem that is shared, not only by educational systems at a global level, but also by different social environments such as the occupational field in many countries. In this sense, Moreno (2017) has indicated that $52.3 \%$ of internet content is written in English and yet, only $26.2 \%$ of the users of the Network speak this language. All of the above has awakened a renewed interest of teachers, educational institutions, governments and researchers who have tended to address the problem from the scientific perspective developing studies aimed at making methodological proposals in favor of the development of reading comprehension skills in English. However, the context of basic and secondary education is scarce in this type of studies.

This document explores the general context of English teaching and presents an overview of reading comprehension in English in Colombia. Additionally, an approach is made to the challenges of reading comprehension in English as a foreign language in order to propose methodological suggestions that facilitate the improvement of the reading comprehension processes in this language. 


\section{English Language Teaching in the Last Decades}

Decades ago, the approaches, methods and models for teaching a foreign language were permeated by approaches whose main objective was the acquisition of the linguistic code of the language by the learner (Richards \& Rodgers, 2017). However, since the mid-twentieth century, thanks to the research that has been conducted in regards to language teaching and the contribution of cognitive psychology, a communicative vision of the language that focuses more on the teaching process was introduced. From this new perspective, both: the role of the teacher and the role of the student have been progressively transformed, being the latter, the one who acquires a leading role in their own learning process. For this reason, new concepts like self-direction, autonomy and self-regulation have been introduced. These concepts seek to highlight the preponderant role of students in their development as foreign language learners.

In this order of ideas, such a change in the vision and purpose of teaching and learning of languages, presents great challenges to the education system in general, not only on learners but also on teachers. The latter must expand its view of the teaching-learning processes of a foreign language, understanding that if you want to achieve a transformation of students, schools and society; it is mandatory to have clear that the first step that teachers need to consider to achieve this goal is to get a change in themselves, their practices and their conceptions about teaching. For this reason, and taking into account the fundamental role of the language teacher in the training processes and considering the challenges posed by the plurilingual world where we live, teachers must think beyond traditional teaching methods and conceive a curriculum and a pedagogy that gravitate around specific educational scenarios where there are particular needs, being the development of reading comprehension in a foreign language, a neuralgic aspect that has to be prioritized by teachers in their classrooms and in their curricular designs. According to Davini (2008), teachers must permanently work in the pursuit of their professional growth in order to improve their performance, since there is a direct correlation between the education of the teacher and the benefits that students can obtain from the processes that they develop.

\section{What about English Language Teaching in Colombia?}

One of the main goals of the Colombian educational system is that the students of eleventh grade can be in a B1 level of communicative competence in English according to the parameters established by the Common European Framework of Reference (CEFR, 2018) (Note 1).

However, the level of competence of a learner is determined only by evaluating the reading and writing competences through the evidence-based model designed and presented by the national government, with the "Saber Once" test. To achieve the goal of having secondary learners in a B1 level of proficiency in English, suggests a first challenge for language teachers: they must have achieved at least an internationally certified B2 level of proficiency in English within their disciplinary training if they want to help learners to achieve a B1 level. Then, the language teacher must be at the forefront in their knowledge and updating in order to meet the requirements and needs around the development of reading comprehension and the teaching of English as a foreign language.

However, in addition to the permanent search for professional qualification, language teachers have to lead processes of transformation and curricular adaptation in the institution where they work; they should do it in a critical and sustained manner. The need to work at least 4 hours per week of English in the institutions is imperative, but at the same time it has limitations if structural and methodological changes are involved.

These changes are based on the provisions of the CEFR regarding the number of hours of instruction and language exposure that students of a foreign language must have to advance from one level to another, especially in a macro-skill as complex and demanding as reading, which in our country is regulated by the Technical Norm NTC 5580 of the Colombian Institute of Technical Standards (ICONTEC). Today a large percentage of educational institutions in the country have an insufficient number of hours of English instruction, being only two hours weekly, the average number that predominates.

Another challenge assumed by language teachers to achieve the development of communication skills in English is the fact that they need to consider training spaces as the most appropriate places to investigate, experiment and share ideas collectively with other members of the educational community reflecting and making decisions to solve problems or decide what is relevant and how learning must take place, all this, with the intention of building their own knowledge through their own research processes. From the beginning of the Critical Curriculum Theory (CCT), a model capable of making the teacher do research within the classroom has been sought. The main purpose of this is to avoid that teachers become subject to school practices thought and imposed by researchers who ended up making curricular bets that responded to the interests of few people. 
It is important to clarify that the investigative work conducted by teachers must be carried out through a collective, dialogical and systemic construction, where the family, the student, the school, other teachers, researchers and the representation that the state has in educational matters must take part. According to Correa (2004), who has indicated that the permanent training of the teacher is an important but insufficient element in the development of better curricular experiences, individual and social transformation is only possible when there is a contextualized curriculum which is articulated with the processes developed by the students, with an active participation of the fundamental actors of the educational process in a cooperative and systemic construction.

\section{Reading Comprehension Panorama in English as a Foreign Language in Colombia}

Changing the scenario, and after having socialized the limitations experienced when teaching English in Colombia, it is important to indicate that students also encounter many challenges when learning a language, especially when learning to read, since this skill requires, not only time and the use of appropriate materials, but a didactic that matches the motivation and involvement of foreign language learners. McNamara (2010), states in this regard, that the number of students who have difficulties to respond appropriately to questions concerning texts written in English is significant especially when learners are monolingual. This situation is not new among learners; it is common to observe frustrated students when they have to read in English, especially when the 21st century has been distinguished by a broad development of technology, communication and social networks that have impacted daily life, in addition to globalization, which has brought as a consequence, new challenges to humanity, including the constant exposure to a large amount of information written in this language.

Contextualizing English learning in Colombia, it can be said that reading comprehension in this language is approached from three levels: literal, inferential and critical, being the latter the ideal one, and therefore the reading comprehension level that requires more effort. As expressed by Van Dikj and Kintsch (1983), at the literal level the reader recognizes the surface code, that is, interprets the lexicon and analyzes it at the syntactic level. On the inferential level, the reader can recognize the base text and at the critical level, readers are able to abstracts the text to propose a new text where they expose their own arguments.

When looking at the analysis of international tests such as PIRLS (Progress in International Reading Literacy) (Note 2) or PISA (Program for International Student Assessment) (Note 3), Colombian students in general do not reach a satisfactory level in these test.

In general terms, only 1 in 10 Colombian children are able to recognize and interpret information in a text, make inferences, establish relationships between different contents and make generalizations based on the information obtained.

Therefore, it is necessary to promote the exposure of students to the development of activities that promote interpretation and critical thinking from reading. In this order of ideas, Fernández and Montero (2005), affirm that, the text has no meaning in itself, but it acquires meaning for the writer and for those who interpret the text. Therefore, it becomes an urgency to encourage students to have comprehension schemes that enable interpretation and analysis, which help them to develop ways to present their points of view and to expose their own criteria from reading a text.

Given this panorama, what options are available? Speaking specifically about the development of reading comprehension in English as a foreign language, the teacher could build a collective proposal and implement strategies, methods and / or curricular designs that promote the generation of a reading culture in English among students, to achieve an improvement in the reading comprehension processes in the Foreign Language. The starting point would be to understand that "learning to read requires not only to develop cognitive processes, but also to acquire the particular sociocultural knowledge of each discourse, of each concrete practice of literacy" (Cassany, 2006). From this perspective, the knowledge acquired in the English class, would allow spaces for reflection on the social reality and thus assume a critical position against it from a reader analysis that transcends the literal level. Now, to conceive reading as a process of sociocultural understanding, needs to understand that it involves the interaction between the text-author, the reader and society, that is, in the words of Serna \& Díaz (2014) "a reader with a greater knowledge of social and disciplinary reality will have a high level of understanding"(p. 172).

Additionally, although the reflection that will be presented below corresponds to a research done in the mother tongue, we consider that it is applicable to critical and argumentative reading in English. Serna and Díaz (2014) have indicated that:

"To develop a critical reading implies going beyond the literal and inferential understanding, is to take a stand 
against the discourses of culture, in order to unveil power relations and abuse of it. Therefore, to make a critical reading is to have an attitude to be able to value and position yourself against the discourses of culture" (p. 175).

Therefore, our curricula are required to seek a change in regards to reading, understanding it, as a superior, interactive and dynamic process that has a liberating and emancipatory nature of diverse opinions.

Therefore, it must strive for emerging didactics that are collectively constructed but that value individuality and subjectivity within the framework of complexity and critical thinking. A hard task that can be achieved when we understand that the human being has capacities that require educational institutions, teachers and all educational actors in general to understand and promote through their methodological, didactic and curricular conception expressed by Van Dijk (2004) when it is indicated that that understanding a discourse means being able to create a mental model and if the discourse is familiar to the reader, its understanding will be much more accessible, since in the understanding of the texts, the situation models play a decisive role because they are fundamental to grant coherence to the text.

\section{Conclusion}

Through this article, we have reflected on the current panorama of reading comprehension in English in our country, analyzing the perspective teachers, students and of the education system in general. This analysis has focused on the challenges that are inherent to them in order to suggest possible methodologies, strategies and curricular reforms that can be addressed in search of progress and improvement of reading comprehension in English from our classrooms and achieve significant effects on reading towards a critical level of comprehension.

Finally, this document encourages teachers and educational researchers to conduct more studies on reading comprehension in English in Colombia, since it broadly explores the real needs and deficiencies of teachers and students in this country, establishing possible methodologies in order to face the current challenges of reading comprehension in English in our country. For all this, documented interventions that require action routes on the subject matter are required. On the other hand, the analysis presented so far is relevant if one takes into account that this has been a field that has not been explored well in the basic and secondary education levels. In addition, it is important to emphasize that more research efforts are required at the primary level since it is evident that the work of reading comprehensively in a foreign language since the first grades, allows children to expand their vocabulary, interpret it in written contexts and find meaning and usefulness to the language they are leaning which are indispensable factors to guarantee learning.

\section{References}

Cassany, D. (2006). Tras las lineas. Barcelona: Anagrama.

Council of Europe. (2018). Common European framework of reference for languages: Learning, teaching, assessment. Cambridge, U.K.

Correa, C. (2004). Currículo dialógico, sistémico e interdisciplinar. Bogotá, Colombia. Ediciones Magisterio.

Davini, M. (2008). Métodos de Enseñanza: Didáctica General para Maestros y Profesores. Buenos Aires. Ediciones Santillana.

Fernández, M., \& Montero, S. (2005). La lectura en segundas lenguas: análisis de la contextualización previa y sus implicaciones metodológicas. Porta linguarum, 3, 35-44. Retrieved from http://www.ugr.es/ portalin/ articulos/PL_numero3/fernandez-lectura.pdf.

McNamara, D. S. (2010). SERT: Self-explanation reading training. Discourse Processes, 38, 1-30. https://doi.org/10.1207/s15326950dp3801_1

Moreno, G. (2017). Qué idiomas habla Internet? Madrid. Statista. Retrieved August 8th, 2018, from https:/es.statista.com/grafico/7736/la-mitad-del-contenido-de-internet-esta-en-ingles/

Richards, J. C., \& Rodgers, T. S. (2017). Approaches and methods in language teaching (3rd ed.). Cambridge: Cambridge University Press.

Serna, J., \& Díaz, J. (2014). Propuesta didáctica para la comprensión crítica en la Universidad La Gran Colombia. Cuadernos de Lingüística Hispánica, 25, 165-180.

Van Dijk, T. (2004). Discurso y Dominación. Retrieved from http://www.bajofuego.org.ar/textos/Discurso_y_ dominacion.pdf

Van Dijk, T. A., \& Kintsch, W. (1983). Strategies of discourse comprehension. New York: Academic Press. 


\section{Notes}

Note 1. The Common European Framework of Reference for Languages (CEFR) is the system that defines and explains the different levels of expression and oral and written comprehension for languages such as English. This standard is used mainly in Europe although there are other countries that also take it as a reference. It is very useful for teachers, since it allows them to evaluate the linguistic competences of their students. The CEFR comprises 6 common levels of reference for all languages: three blocks (basic level or A, independent or B and competent or $\mathrm{C}$ ), which are divided into two sub-levels: 1 and 2.

Note 2. The Study of Competing International Progress (PIRLS) is an assessment of reading comprehension, which has monitored trends in student performance over a five-year period in countries around the world since 2001. The target population is represented by enrolled students who have an average of four years of schooling, that is, on average 9.5 years of age.

Note 3. The Program for International Student Assessment (PISA), assesses the development of the skills and knowledge of 15-year-old students through three major tests: reading, math, and science. The Organization for Economic Cooperation and Development (OECD) applies this standardized test every three years, since the year 2000 , and in each of the applications it deepens into one of the three areas mentioned

\section{Copyrights}

Copyright for this article is retained by the author(s), with first publication rights granted to the journal.

This is an open-access article distributed under the terms and conditions of the Creative Commons Attribution license (http://creativecommons.org/licenses/by/4.0/). 